\title{
Prevention of epidural
}

\section{postlaminectomy fibrosis using absorbable mechanical barriers in Wistar rats}

\author{
Prevenção de fibrose peridural pós-laminectomia usando barreiras mecânicas \\ absorvíveis em ratos Wistar
}

Joacil Carlos da Silva Junior

Tese de Doutorado, Universidade Federal de Pernambuco (UFPE), Área Neuropsiquiatria-Neurocirurgia, Recife PE, 2011.

Orientador: Marcelo Moraes Valença.

Correspondence: Joacil Carlos da Silva Junior; Rua Frei Matias Teves 280 / Sala 705; 50070-450 Recife PE - Brasil; E-mail: jneurosurgery@gmail.com

\begin{abstract}
Introduction: Peridural fibrosis (PF) is a physiological tissue response to surgical trauma after the opening of spinal canal by laminectomy. The exacerbation of this phenomenon can create scar adhesions between the dura mater, spinal roots, vertebrae, and paraspinal muscles with traction or compression of neural structures. PF can lead to genesis of failed-back surgery syndrome (FBSS), which is defined as persistence or intensification of painful symptoms after spinal surgery. Methods of mechanical barrier between the meninges and paraspinal muscles are often used in order to prevent PF and FBSS. Methods: The experiment used 32 Rattus norvegicus, Wistar lineage, submitted to lumbar laminectomy and divided into four groups: Control, Collagen, Lactic Acid, and Biopolymer. The Control Group Dura Mater was not covered. The Collagen Group received absorbable porcine gelatin, the lactic acid one received lactic acid polymerized membrane, and the biopolymer, sugar cane biopolymer membrane. After 90 days, the animals were killed, and histological sections were performed. The parameters of foreign body reaction, absorption, PF, adhesion, traction, and compression were studied using an intensity scale. Necrosis, abscess and epidural venous engorgement were classified according to presence or absence. Results: The groups did not differ in the parameters of foreign body reaction, absorption, PF, adhesion, traction, and compression. There was no epidural venous engorgement in any animal. The biopolymer group showed a significant difference compared to other groups in the parameters of necrosis $(p=0.0192)$ and abscess $(p=0.0033)$. Conclusions: The absorbable membranes used in this experiment did not show efficacy in reducing the occurrence of PF, adhesion, and neural traction. The use of sugar cane biopolymer triggered unfavorable phenomenon (necrosis, abscess, and neural compression) for its use to prevent PF.
\end{abstract}

Key words: spine, laminectomy, failed fack surgery syndrome, biopolymer, animal experimentation, rats. 